\title{
LA PROBLEMÁTICA ADMINISTRATIVO-FISCAL DE UN PAÍS NACIENTE MÉXICO, 1821-1824
}

\author{
THE ADMINISTRATIVE-FISCAL PROBLEMS \\ OF A NASCENT COUNTRY \\ MÉXICO, 1821-1824
}

\author{
Luis JÁUREGUI \\ Instituto de Investigaciones Dr. José María Luis Mora \\ ljauregui@mora.mx
}

Resumen

Este estudio parte de la idea de que no se puede entender la situación financiera de los gobiernos postindependentistas sin tener conocimiento de la administración que se hacía cargo de los recursos públicos. En las siguientes páginas se analizan las oficinas que resguardaban los dineros públicos en una época de guerra interna; concretamente, la que llevó a la consumación de la independencia de Nueva España. Se concluye sobre la razón para el establecimiento del ministerio de hacienda. También se sugiere el motivo por el cual las juntas provinciales procedieron a formar sus propias administraciones financieras y se aporta una razón más para el establecimiento del federalismo en 1824. El estudio explora el destino de los intendentes, cómo paulatinamente fueron perdiendo razón de ser en la administración provincial del México independiente hasta su desaparición por motivo del establecimiento de la nueva administración financiera de la república federal.

Palabras clave: México en el siglo xıx; administración pública; impuestos; diputaciones provinciales; intendentes.

\begin{abstract}
The study of administrative aspects of early independent Mexico is crucial to understand its financial woes. This article is a study on the operation of Mexico's treasury offices during the last months of the colonial period. In opposition to a superintendent, the paper also gives a plausible reason for the establishment of a ministry of finances. Furthermore, it discusses the motive behind the formation of the provincial deputations' own financial administration offices which is an additional reason for the establishment of federalism in 1824. Lastly, because of the new federal administration scheme, this article discusses the intendants' destiny and final demise.
\end{abstract}

Keywords: Nineteenth-century Mexico; public administration; taxes; provincial deputations; intendants. 
Información del artículo

Recibido: 30 de septiembre de 2019.

Aceptado: 27 de enero de 2020.

DOI: 10.22201/iih.24485004e.2020.59.70991

Hace algunos años, en 2016 y con motivo de los 170 años de su fundación, la tesorería de la federación me invitó a hacer una historia de esa oficina. Por distintas razones, propias de los planes echados a andar por el gobierno, el proyecto no progresó, pero me quedó la idea de que alguien debía hacer un trabajo histórico de esa dependencia. Primero, habría que preguntar ¿qué es la tesorería? La mayoría de los mexicanos de hoy en día no tiene idea de lo que es esa oficina. Antes, recuerdo, nos pagaban con unos cartoncitos (recuerdo que eran café y luego azules) que se llamaban cheques de tesorería, mismos que podían cambiarse en muchos lugares e incluso se podían usar para pagar en tiendas de autoservicio. Todavía en esos tiempos la gente, o al menos los que trabajaban en el servicio público, tenía una idea de lo que era la tesorería de la federación. Desde que aparecieron las transferencias electrónicas, casi nadie conoce ni la oficina (donde el actual presidente da sus conferencias mañaneras) ni al titular de la misma.

El desconocimiento actual de la tesorería ha llevado a cierto olvido de la misma por parte de los historiadores. ${ }^{1}$ Esto ha contribuido a la dificultad

${ }^{1}$ Múltiples historiadores han atendido el estudio de la situación financiera de los últimos años del siglo XVıII y hasta el establecimiento del confederalismo fiscal en 1824. Sin menospreciar a ninguno de análisis más específico, destacan los trabajos de visión general de Luis Jáuregui, La real hacienda de Nueva España. Su administración en la época de los intendentes, 1786-1821 (México: Universidad Nacional Autónoma de México, Facultad de Economía, 1999); Carlos Marichal, La bancarrota del virreinato. Nueva España y las finanzas del imperio español, 1780-1810 (México: El Colegio de México/Fideicomiso de las Américas, 1999); y Bankruptcy of Empire. Mexican Silver and the Wars between Spain, Britain and France, 1760-1810 (Nueva York: Cambdrige University Press, 2007); Ernest Sánchez Santiró, La imperiosa necesidad: crisis y colapso del erario de Nueva España (1808-1821) (México: Instituto de Investigaciones Dr. José María Luis Mora/El Colegio de Michoacán, 2016); Barbara Tenenbaum, "Sistema tributario y tiranía: las finanzas públicas durante el régimen de Iturbide, 1821-1823”, en Las finanzas públicas en los siglos XVIII-XIX, coord. de Luis Jáuregui y José Antonio Serrano Ortega (México: Instituto de Investigaciones Dr. José María Luis Mora/El Colegio de Michoacán/El Colegio de México/Universidad Nacional Autónoma de México, Instituto de Investigaciones Históricas, 1998); Leonor Ludlow, "Élites y finanzas públicas durante la gestación del Estado independiente, 1821-1824”, en Hacienda y política. Las finanzas públicas y los grupos de poder en la primera República Federal Mexicana, coord. de José Antonio Serrano Ortega y Luis Jáuregui (México: El Colegio de Michoacán/Instituto de 
para comprender el éxito o fracaso de las finanzas públicas de casi todo el siglo XIX. Por tal motivo, como parte de un proyecto de largo alcance sobre el establecimiento y funcionamiento de la tesorería en la etapa nacional planteo la siguiente pregunta: ¿̨ómo se evitó la desintegración de la fiscalidad en el tránsito de los últimos meses del dominio español a los primeros días de la regencia mexicana? Con base en esta cuestión surge otra pregunta: ¿cómo funcionaban las tesorerías en la etapa nacional? En concreto, analizo la transición de la gestión de los ingresos y los gastos públicos de los últimos años de Nueva España a los primeros meses del periodo independiente. El estudio tiene dos pretensiones. Por una parte discute sobre las administraciones paralelas del ejército y de las diputaciones provinciales en la gestión de los recursos públicos de los últimos meses de la dominación española. Por otro lado, y como aspecto relacionado con lo anterior, analiza los pormenores del establecimiento del ministerio de hacienda de la nueva nación independiente, el trabajo de las diputaciones provinciales y el destino de los intendentes.

Las últimas tesorerías novohispanas y el ejército trigarante

Con y sin constitución, en tiempos del liberalismo o de la restauración, las urgencias de la llamada guerra de independencia iniciada en 1810 forzaron a las autoridades del virreinato de Nueva España a discurrir una fiscalidad diferente a la que por el mismo tiempo se discutía y aplicaba en la península. Guiada más por la necesidad de pagar a la tropa y a la lista civil que por seguir los postulados ideológicos, la característica principal de esta fiscalidad fue que, con la ayuda de las reformas gaditanas aunque sin aplicarlas a rajatabla, para generar más recursos el erario novohispano decidió eliminar los privilegios y regímenes especiales de tributación heredados de siglos atrás. ${ }^{2}$

Investigaciones Dr. José María Luis Mora, 1998); Jesús Hernández Jaimes, La formación de la hacienda pública mexicana y las tensiones centro-periferia, 1821-1835 (México: Instituto de Investigaciones Dr. José María Luis Mora/El Colegio de México/Universidad Nacional Autónoma de México, Instituto de Investigaciones Históricas, 2013).

${ }^{2}$ Para las contribuciones adoptadas en Nueva España durante los años de la insurrección y para una cronología más específica de estos cambios, véase Ernest Sánchez Santiró, “Guerra y restauración del antiguo régimen fiscal en Nueva España: la Junta Menor de Arbitrios de 1815”, Jahrbuch für Geschichte Lateinamerikas, n. 48 (2011): 57-81. Para los detalles de todo el proceso, véase Sánchez Santiró, La imperiosa necesidad..., capítulo IV y epílogo. 
En los últimos años de la dominación española, la insurgencia perdió intensidad, a juzgar por el hecho de que la autoridad misma aceptó la disminución de la gravedad de la coyuntura bélica. ${ }^{3}$ Por otro lado, aunque materia de controversia, sabemos que la situación fiscal del territorio novohispano acusó un deterioro considerable en los pocos meses que transcurrieron entre fines de 1819 y el verano de 1821. Sánchez Santiró destaca dos razones para que esto ocurriera: la restauración del régimen constitucional y la escisión del ejército realista o lo que Moreno Gutiérrez llama "la trigarancia". ${ }^{2}$

Y es que desde los últimos años de la dominación española y los meses posteriores a la culminación de la independencia las provincias desobedecieron al centro en términos de la provisión de recursos, mientras que los contribuyentes se habían quedado con la idea de que la nueva vigencia de la constitución, declarada en marzo de 1820, los liberaba del pago de sus impuestos. ${ }^{5}$ A manera de ejemplos, Sánchez Santiró detalla cómo en mayo de ese año la diputación provincial de Yucatán eliminó el estanco del tabaco aun frente al reclamo que por esta acción recibió desde la autoridad en la ciudad de México. Igualmente, en agosto de ese año, en un bando el jefe político de Zacatecas acusaba a muchos individuos de que "por el nuevo sistema que induce la constitución política de la monarquía, todo giro es libre y que por lo mismo están exentos de pagar aquellos derechos [de la] hacienda pública". Se puede agregar como causa del deterioro fiscal de los últimos meses de Nueva España el decreto de las cortes de junio de 1821 en el que se reducía el diezmo minero a $3 \%,{ }^{6}$ disminución que no llevó a un incremento en la colectación total del impuesto, principalmente por cuestiones administrativas y deterioro infraestructural de la explotación minera.

La escisión del ejército realista desde inicios de 1821 redujo sustancialmente los recursos destinados a la ciudad de México y generados en

${ }^{3}$ Sánchez Santiró, La imperiosa necesidad..., 390-392.

${ }^{4}$ Sánchez Santiró, La imperiosa necesidad..., 392; Rodrigo Moreno Gutiérrez, La trigarancia. Fuerzas armadas en la consumación de la independencia Nueva España, 1820-1821 (México: Universidad Nacional Autónoma de México, Instituto de Investigaciones Históricas/ Fideicomiso Teixidor, 2016).

${ }^{5}$ Esta problemática la relata Canga Argüelles, ministro de hacienda de la monarquía constitucional, para el caso de la península. Voz: "Memoria”, en José Canga Argüelles, Diccionario de hacienda con aplicación a España, v. 2 (Madrid: Imprenta de don Marcelino Calero y Portocarrero, 1833-1834), 234-293.

${ }^{6}$ Sánchez Santiró, La imperiosa necesidad..., 393-397. 
Acapulco, el Bajío y Veracruz. Esta situación se fue agravando conforme pasaron los primeros nueve meses de ese año. A medida que más regiones se fueron incorporando al movimiento de Iturbide y al amparo del Plan de Iguala, la capital virreinal se vio paulatinamente más afectada por la falta de recursos necesarios para el pago de su guarnición y su lista civil. En abril el recaudador de alcabalas de la provincia de Guanajuato comunicaba al director general de aduanas en la ciudad de México sobre una instrucción recibida de parte de Iturbide. En tal misiva Iturbide le comunicaba que, dado que Guanajuato se había separado del mando de Apodaca, todos los ramos de hacienda quedaban "a disposición de los respectivos jefes de división de este ejército de mi mando”. En consecuencia, le prohibía que - sin orden del comandante general de la provincia, que a la sazón era el coronel Anastasio Bustamante- diera salida a cantidad alguna que fuera producto de las alcabalas. Por otro lado, el alcabalero guanajuatense relataba que Iturbide le prohibía obedecer las instrucciones de la ciudad de México bajo la pena de ser acusado de lesa nación. Para efectos de lo que aquí relato, lo más interesante de esta carta era que Iturbide le instruía al funcionario provincial que, en caso de que fuera necesario, debía remitir los recursos a la "tesorería o pagaduría de este ejército más inmediata". ${ }^{7}$ Esta carta confirma lo que señala Moreno Gutiérrez en el sentido de que el año de 1821 fue un tiempo de "guerra por el control de las alcabalas" que, independiente de los reglamentos específicos de este derecho (principalmente el de Santa Anna en Veracruz) muestran cómo Iturbide pretendió asfixiar de recursos al gobierno de Apodaca. Cierto que esta asfixia mantuvo la recaudación en el mando civil pero destinó, de manera real o virtual, los recursos de alcabalas, tabaco, préstamos, donativos y confiscaciones a las tesorerías militares. A estas tesorerías se les denominaba "tesorería militar de la [número] división del ejército imperial mexicano de las 3 garantías". ${ }^{8}$

La aparición de las tesorerías militares lleva a comentar que durante la rebelión en Nueva España se mantuvo el complejo sistema de cajas y, de manera muy reducida, sus transferencias. ${ }^{9}$ Sin embargo, también se hicieron

${ }^{7}$ Pascual José de Viderique a Marino Ignacio Quijano, Salamanca, 30 de abril de 1821, Archivo General de la Nación (en adelante AGN), Indiferente virreinal, caja 4829, exp. 49.

${ }^{8}$ Moreno Gutiérrez, La trigarancia..., 347, nota 132. Aquí el autor señala dos tesorerías de este tipo: la de Zitácuaro en la provincia de Michoacán y la de Amecameca en la de México.

${ }^{9}$ El asunto del deterioro de las transferencias fue destacado por Jonh J. TePaske, "La crisis financiera del virreinato de Nueva España a fines de la colonia”, en Jáuregui y Serrano 
presentes un conjunto de depositarías como las "tesorerías independientes" 10 y las que, al amparo de la ley, se crearon en los ayuntamientos constitucionales y las diputaciones provinciales. ${ }^{11}$ La intuición nos dice que como se habían creado una multitud de arbitrios para pagarle a las tropas (regulares y milicias), había al parecer depositarías - si bien informalesen muchos ranchos y haciendas del centro de Nueva España. ${ }^{12}$

Después de consumada la independencia, se mantuvo la estructura administrativa heredada de tiempos virreinales; la diferencia es que, aún más que en el pasado, el dinero recaudado por multitud de impuestos, derechos y arbitrios permaneció en estas tesorerías y depositarías provinciales o locales. Lo que sí se consideraba recurso en la tesorería de la ciudad de México era el que se generaba en el sistema de alcabalas que nunca dejó de funcionar para el cobro de alcabalas y diversos derechos creados durante la contienda armada. ${ }^{13}$ Esta tesorería matriz, a las órdenes del gobierno virreinal y posteriormente de la regencia, se ha de haber visto en serios problemas tanto por el restablecimiento del orden constitucional, que implicó cambios administrativos sustanciales en la manera de administrar las finanzas, como por la referida asfixia que paulatinamente implementaron las tropas trigarantes sobre la capital novohispana. Más aún, es de destacarse que, antes de la escisión del ejército, la propia autoridad virreinal enfrentaba una problemática que, en mi opinión, facilitó las cosas para las tropas rebeldes en materia de recaudación, información y distribución de recursos fiscales.

El 5 de enero de 1819 el gobierno de Apodaca emitió una orden que buscaba tener información sobre el estado en que se encontraba la real

Ortega, Las finanzas públicas..., 90-109. La propia autoridad virreinal se había percatado de este problema y extendió un "Decreto superior sobre auxilios recíprocos", Gaceta del Gobierno de México, México, 15 de febrero de 1816.

10 "Convenio de evacuación de tropas del ejército en Durango", 3 de septiembre de 1821, en Documentos para la historia fiscal del erario de Nueva España, (1808-1821), comp. y prólogo de Ernest Sánchez Santiró (México: Instituto de Investigaciones Dr. José Luis María Luis Mora, 2017), documento 142.

11 Véase el artículo 335, fracción cuarta, de la Constitución de Cádiz, en Felipe Tena Ramírez, Leyes fundamentales de México, 1808-1991, 16a. ed. (México: Porrúa, 1991), 98-99.

12 Ernest Sánchez Santiró, "Los mecanismos de financiamiento de la contrainsurgencia, 1810-1821”, en El sustento económico de las revoluciones en México, coord. de Leonor Ludlow (México: Universidad Nacional Autónoma de México, Instituto de Investigaciones Históricas, 2013), 95-122.

${ }^{13}$ Veáse el interesante mapa 2 en Sánchez Santiró, La imperiosa necesidad..., 319. 
hacienda. No fue sino hasta diez meses después que el tesorero general le respondió al virrey.

El estado de la real hacienda del reino, tanto en sus ingresos, como en sus erogaciones y monto total de su deuda, no puede saberlo esta tesorería, aunque es la general, porque todas las foráneas de provincia y sufragáneas gobiernan con independencia, cada una tiene privativo conocimiento de los que maneja, sin transmitirlo a esta de nuestro cargo, aun cuando recibía los remanentes de todas, antes de la insurrección $\left[\ldots . .{ }^{14}\right.$

El tesorero proponía que, para tener una idea más clara, era conveniente hacer la pregunta al tribunal de cuentas, pero que tal procedimiento podía tardar, pues esta oficina debía hacer acopio de los libros contables de todas las cajas. Para complementar esta sugerencia, el tesorero recomendaba que el virrey "se sirva circular orden a todas las tesorerías para que cada una de por sí forme un estado instruido y lo remita al citado tribunal". La contaduría de cuentas respondió que, aun y cuando pudiera reunir las cuentas de las cajas éstas no quedarían completas pues faltaban varias cuentas "respectivas a las [tesorerías] de Guadalajara, Durango, Oaxaca, Valladolid, Rosario y Acapulco desde el año de 1811". Tanto la mesa de liquidaciones como los propios contadores de cuentas ratificaron entonces la sugerencia de los ministros de la tesorería de que el propio virrey extendiera la circular a todas las tesorerías del reino. ${ }^{15}$

Para cuando Apodaca envió la circular a las tesorerías en marzo de 1821 habían pasado más de dos años, se había dado un cambio de régimen en la monarquía y estaba en marcha la escisión del ejército nacional de Nueva España. ${ }^{16}$ En los primeros días de abril, el intendente de Guanajuato acusó recibo. ${ }^{17}$ Una semana después, y como prueba de que las tesorerías nacionales (las anteriores cajas reales) en las provincias sí tenían la información

${ }^{14}$ Antonio Batres, tesorero de la hacienda pública de Nueva España, al virrey conde del Venadito, México, 8 de noviembre de 1820, AGN, Indiferente virreinal, Real Hacienda, caja 6101, exp. 23.

${ }^{15}$ Los contadores del tribunal de la contaduría de cuentas a los ministros de la tesorería general, México, 16 de marzo de 1821, AGN, Indiferente virreinal, Real Hacienda, caja 6101, exp. 23.

${ }^{16}$ Circular con firma "Del Venadito”, México, 24 de marzo de 1821, AGN, Indiferente virreinal, Real Hacienda, caja 6101, exp. 23.

${ }^{17}$ Fernando Pérez Marañón al virrey conde de Venadito, Guanajuato, 3 de abril de 1821, AGN, Indiferente virreinal, Real Hacienda, caja 6101, exp. 23. 
que tanto tiempo buscó el virrey, el intendente de San Luis Potosí enviaba a la ciudad de México cuadros detallados de los ingresos, gastos y deudas registrados por la tesorería nacional de esa provincia. ${ }^{18} \mathrm{Al}$ menos para el caso de las provincias centrales del espacio virreinal, la circular de Apodaca le hizo el trabajo al ejército trigarante, pues unos días después -a juzgar por el caso de Guanajuato- éste ocupaba las tesorerías que además contaban con información financiera actualizada. ${ }^{19}$

\section{El funcionamiento de las cajas reales/nacionales}

En el lustro que va de 1785 a 1789 la real hacienda de Nueva España destinaba poco menos de la mitad para los situados a otro territorio que no fuera lo que después sería México independiente. Si la división se hace por actividades, el erario gastaba principalmente en cuestiones militares, gastos de hacienda y en un tercer lugar las remisiones a la metrópoli. ${ }^{20}$ Debido a los conflictos bélicos provocados por la ambición napoleónica en Europa, esta hacienda real, que en el ámbito internacional proyectaba la imagen de poseer recursos inagotables, cayó en bancarrota a fines de la primera década del siglo Xıx. ${ }^{21}$

Estas afirmaciones son el resultado del análisis de los documentos generales de la real hacienda, aquellos que intercambiaban virreyes y ministros de hacienda en la corte de Madrid. Sin embargo, cabe preguntar ¿cómo funcionaban las tesorerías novohispanas, las mismas que proveían recursos en numerario a la caja de México que a su vez los transportaba al puerto de Veracruz en donde después se distribuía para el pago de fuerzas navales, deudas y defensa?

Creo que la pregunta es particularmente relevante para los años de la guerra de independencia, toda vez que en aquella época se modificó el sistema

${ }^{18}$ Manuel de Acevedo al virrey de Nueva España, San Luis Potosí, 11 de abril de 1821, AGN, Indiferente virreinal, Real Hacienda, caja 4829, exp. 49.

${ }^{19}$ A fines del verano de 1836 la oficina de rezagos de la secretaría de hacienda pedía las cuentas de la tesorería militar de Pátzcuaro para 1821. El comisario general de Michoacán respondía que "existen en el archivo de esta subcomisaría [pero] no están duplicadas [y] son bastante voluminosas”. Unzueta a Martínez de la Comisaría de Michoacán, México, 23 de agosto de 1836, y Manuel Martínez, de la comisaría de Michoacán al jefe de la oficina de rezagos, Juan A de Unzueta, México, 7 de octubre de 1836, ambas en AGN, Archivo Histórico de Hacienda, v. 902, exp. 1.

${ }^{20}$ Sánchez Santiró, "Los mecanismos de financiamiento...”.

${ }^{21}$ Marichal, Bankruptcy of Empire..., 173, 234-239. 
de tesorerías heredado de tiempos borbónicos. En este sentido, Sánchez Santiró señala varios aspectos de este cambio. En primer lugar, se dio un incremento sustancial en el gasto militar y la ya mencionada suspensión de pagos en la forma de situados y las remisiones de fondos a la metrópoli. Por otro lado, aunque en cierta forma se aplicó el cambio hacia una fiscalidad liberal amparada en el papel por los decretos y la constitución de Cádiz de $1812,{ }^{22}$ en la realidad tales modificaciones respondieron plenamente a un afán recaudatorio. De ahí que haya aparecido la fiscalidad extraordinaria que de manera informal autorizaba a las antiguas cajas reales (nacionales después de marzo de 1820) y otras de menor jerarquía a realizar pagos militares.

La operación de las tesorerías dependía, por una parte, de un conjunto de oficinas recaudadoras que generalmente conocemos como alcabalas y estanquillos. ${ }^{23}$ En el primer caso se cobraban los derechos de alcabala y pulques; en el segundo se expendía tabaco, papel sellado, billetes de lotería, pólvora $^{24}$ (aunque supongo que el producto se hallaba en algún polvorín alejado de la población) y naipes. De un porcentaje de la recaudación por estos conceptos los administradores hacían los gastos que se ofrecían de las rentas del tabaco, pólvora y naipes. Estos gastos eran, por ejemplo, los de mobiliario para la tercena, luces, escritorio, conducción y mermas. De esos recursos también se debían pagar los arrendamientos de las casas de la alcabala y pulques. Por su parte, también de la recaudación total los alcabaleros cobraban un sueldo fijo $\mathrm{y}$, aparte, los gastos peculiares de la renta. ${ }^{25}$

Los ingresos fiscales que resultaban del comercio exterior quedaban en las tesorerías de los puertos. Los recursos provenientes de los impuestos a la minería se pagaban en las cajas reales (o nacionales) más cercanas a las minas. Los derechos de amonedación y ensaye se pagaban en la tesorería de la casa de moneda o en las cecas provinciales que aparecieron durante

${ }^{22} \mathrm{Al}$ respecto véase el cuadro 1 en Sánchez Santiró, "Los mecanismos de financiamiento...”, 106.

${ }^{23}$ Se debe agregar la renta de correos, pero esta oficina dependía del ministerio de gobernación y no del de hacienda. Hernández Jaimes, La formación de la hacienda pública mexicana..., 133.

${ }^{24}$ María Eugenia Romero Sotelo, Minería y guerra: la economía de Nueva España, 18101821 (México: El Colegio de México/Universidad Nacional Autónoma de México, Facultad de Economía, 1997), 96.

${ }^{25}$ Lista que distingue las administraciones reunidas y los sueldos fijos con que están dotadas por los ramos de alcabalas y pulques y el cuanto al que se considera el tanto por ciento en tabaco, pólvora y naipes, con expresión de los sueldos que gozan los interventores, 1822, AGN, Historia, v. 600, documento 261. 
el periodo de la rebelión de independencia. Préstamos y donativos también se pagaban en las cajas reales; en ocasiones los dineros de esta naturaleza y que se hacían al ejército realista también eran depositados en las tesorerías o cajas reales. Ejemplo de esto último fue en abril de 1815 cuando Iturbide solicitó un "socorro a las tropas" al ayuntamiento de Celaya, éste no cumplió con toda la cantidad y don Agustín comunicó que si para finales del día "no entraba en la tesorería la cantidad pedida", se vería en la necesidad de solicitarla como contribución forzosa. ${ }^{26}$

Es lógico concluir que los recursos que se recaudaban en aduanas, alcabalas y estanquillos - excepto los ingresos del tabaco que iban a parar directamente a la tesorería metropolitana- en algún momento llegaran a las tesorerías matrices o foráneas. Puede ser, en el caso que se requiriera numerario para sueldos, pago de tropa, adquisición de materiales, etcétera. Sin embargo, dado que transportar monedas era costoso e inseguro, en realidad se recurría a un sistema de pagos por vía de libranzas. Lo más relevante del tema de las cajas reales es el hecho de que durante el siglo XVIII operaban como un sistema más o menos bien articulado. Al respecto, Sánchez Santiró describe cómo nueve cajas reales remitían sus excedentes a la caja real de la ciudad de México, ésta a su vez enviaba recursos a las cajas deficitarias de Veracruz y Acapulco para gastos militares y situados. Luego había envíos entre cajas; ejemplos son las cajas de Mérida y Campeche que se "apoyaban mutuamente en caso de haber descubiertos en sus cuentas"; estas cajas en ocasiones recibían subsidios desde Veracruz. ${ }^{27}$

Este sistema - al cual referirían múltiples ministros de hacienda de la etapa nacional- se resquebrajó durante los primeros años de la lucha por la independencia. Por ejemplo, en la provincia de Valladolid, donde la insurgencia tuvo fuerte impacto, se dio una desconexión administrativa, de justicia y fiscal, "grupos rebeldes controlaron parte de[1 territorio] y crearon un sistema fiscal alterno para sostener sus tropas". ${ }^{28}$ Para defenderse,

${ }^{26}$ Romero Sotelo, Minería y guerra..., 75.

${ }^{27}$ Ernest Sánchez Santiró, “Genealogía, contenido y consecuencias de un documento contable: las Relaciones de valores y distribución de la Real Hacienda de Nueva España en el quinquenio de 1744 a 1748". En Relaciones de valores y distribución de la real hacienda de Nueva España, 1744-1748, estudio introductorio de Ernest Sánchez Santiró (México: Instituto de Investigaciones Dr. José María Luis Mora/El Colegio de San Luis/El Colegio de Michoacán/Archivo General de la Nación México, 2014), 41-44.

${ }^{28}$ Netzahualcóyotl Luis Gutiérrez Núñez, "La real hacienda y la ordenanza de intendentes de 1786: ensayo sobre su estructura y funcionamiento a partir del caso de Valladolid de Michoacán, 1786-1820”, en Historia de la hacienda pública en Michoacán, 1786-1951, coord. 
las autoridades virreinales ordenaron que fueran los ayuntamientos los que financiaran a las tropas y organizaran su propia defensa. ${ }^{29} \mathrm{~A}$ pesar de que se redujeron, o de plano terminaron, las transacciones entre cajas, lo más relevante fue que la confianza se vio mermada y dejó de operar eficientemente el sistema de libranzas que facilitaba el funcionamiento del sistema de pagos en su conjunto. Este asunto exige un estudio aparte pero ¿qué fue el derecho de convoy si no una manifestación clara de la desconfianza entre la población de que productos y personas llegarían a su destino $?^{30}$

La pérdida de eficiencia del sistema entre cajas construido en tiempos de paz interna se reflejó en la utilización de préstamos provenientes de los consulados de México, Veracruz y Guadalajara, de las diputaciones mineras en distintas regiones del espacio novohispano y de los cabildos eclesiásticos. Estos recursos permitieron al erario colonial hacer pagos de manera más o menos fluida mientras se colectaban los recursos de la fiscalidad ordinaria y extraordinaria. Nada nuevo con respecto a lo que venía sucediendo desde fines del siglo anterior. El problema era, empero, que se expidieron una serie de documentos de deuda que quedaron impagos y que, cuando el erario se recuperó en 1817, fueron adquiridos "de manera indirecta" por quienes apoyaron tal recuperación. Esto los benefició por vía de enormes concesiones del tabaco, bancos privados de rescate de platas, etcétera. ${ }^{31}$ Otro ejemplo del deterioro del sistema de libranzas fue el que se originó en los años 1811-1812 cuando la otrora rica renta del tabaco debió comprar tabaco a los cosecheros, el cual pagó con libranzas. Tiempo después, mientras los recursos del erario se utilizaban para el pago del ejército y no para honrar a estos documentos, se generó un mercado secundario. Los cosecheros endosaron libranzas a terceros y, ante la incertidumbre de que las libranzas serían pagadas por el gobierno, tales endosos llegaron a ser hasta por $80 \%$ de su valor. ${ }^{32}$

de Jorge Silva Riquer (Morelia: Universidad Michoacana de San Nicolás de Hidalgo/El Colegio de San Luis, 2015), 70-71.

${ }^{29}$ Juan Ortiz Escamilla, Guerra y gobierno: los pueblos y la independencia de México (Sevilla: Universidad de Sevilla/El Colegio de México/Instituto de Investigaciones Dr. José María Luis Mora, 1997) 102-109.

${ }^{30}$ Jáuregui, La real hacienda de Nueva España..., capítulo IV.

${ }^{31}$ Sánchez Santiró, La imperiosa necesidad..., 382-388.

${ }^{32}$ Guillermina del Valle Pavón, "El monopolio del tabaco en Veracruz durante la guerra de independencia”, en Revisión histórica de la guerra de independencia en Veracruz, coord. de Juan Ortiz Escamilla (México: Universidad Veracruzana, 2008), 59-62. 
Con un fuerte grado de regionalización de las figuras de ingreso fiscal -en el sentido de que no todos los impuestos que se establecían en el centro se aplicaban en otras regiones ${ }^{33}$ - después de 1817 Apodaca avisaba al ministro de hacienda que la situación del erario iba en recuperación, que no había necesidad de pedir prestado y que los pagos a los funcionarios públicos se habían regularizado. Lo que no dijo el virrey fue que, amén de la mencionada regionalización fiscal, el erario novohispano había contraído el vicio del agio. ${ }^{34}$

La creación del ministerio de hacienda en México independiente

Se dice que la independencia de México se consumó el 27 de septiembre de 1821 porque ese día fue el ingreso del ejército trigarante en la ciudad de México. Desde meses antes, las provincias de la antigua Nueva España se habían adherido al Plan de Iguala promulgado en febrero de ese año. ${ }^{35}$ ¿Cómo fue la administración de los impuestos y su asignación en el nuevo imperio mexicano?

En primera instancia, el poder ejecutivo del nuevo gobierno recayó en una regencia presidida por Agustín de Iturbide, primer jefe del ejército imperial. El poder legislativo lo ejercía una Junta Provisional Gubernativa formada por notables personajes del clero, la política y el ejército de la nueva nación. Los tribunales continuarían tal y como venían haciéndolo al amparo de la Constitución de 1812. ${ }^{36}$

La administración del poder ejecutivo fue similar a la que se tenía en España en la época. Desde los primeros días posteriores a la independencia, la junta provisional gubernativa creó cuatro secretarías de Estado: del interior, de relaciones exteriores, de justicia y asuntos eclesiásticos, de asuntos fiscales y de defensa. ${ }^{37}$

El término nominado secretaría de asuntos fiscales se resolvería días después cuando el secretario interino de hacienda ${ }^{38}$ preguntó si debía continuar

${ }^{33}$ Sánchez Santiró, "Los mecanismos de financiamiento...”, 109-110.

${ }^{34} \mathrm{Al}$ respecto, véase Sánchez Santiró, La imperiosa necesidad..., 383.

${ }^{35} \mathrm{Al}$ respecto, véase el interesante mapa número 5 del libro de Moreno Gutiérrez, $\mathrm{La}$ trigarancia..., 223.

36 Tena Ramírez, Leyes fundamentales de México..., 120-121.

${ }^{37}$ Linda Arnold, Burocracia y burócratas en México, 1742-1835 (México: Consejo Nacional para la Cultura y las Artes/Grijalbo, 1991), 79.

${ }^{38}$ Después de febrero de 1821, este cargo lo desempeñaba el superintendente general Ramón Gutiérrez del Mazo. 
la forma virreinal de administrar las finanzas; es decir, por vía de una superintendencia de Hacienda. ${ }^{39}$ Sobre este asunto es pertinente preguntar ¿por qué hablar de una superintendencia de hacienda si las Cortes la habían eliminado en el decreto del 12 de abril de 1813 y apenas en abril de 1820 se había retomado esta decisión $?^{40}$ Creo que la pregunta del ministro interino de hacienda atiende al deseo de los representantes novohispanos en las cortes españolas de que se mantuviera la relación con la metrópoli pero con una forma de home rule. Aunque ciertamente un anacronismo, conviene considerarlo a la vista de este deseo, manifestado en los catorce puntos que el 3 de noviembre de 1820 presentaron a las cortes los diputados Ramos Arizpe, Michelena, Couto, Cortázar y Fagoaga. ${ }^{41}$ Esta propuesta contiene lo siguiente en sus primeros puntos:

1a. Habrá en México un superintendente general, jefe inmediato de todos los intendentes y directores de rentas de la América Septentrional e islas adyacentes, cuyas principales atribuciones serán: hacer cumplir las reglas establecidas o que se establezcan pertenecientes a lo administrativo y económico de las rentas, y dar a los caudales el giro e inversión a que se destinen. [...]

3a. Habrá en cada provincia, incluso la de México, un intendente, un contador y un tesorero, cuyas oficinas y atribuciones se arreglarán como las de los de la Península, con sólo las modificaciones convenientes para el desempeño de las funciones destinadas al superintendente. ${ }^{42}$

Al parecer, las Cortes ignoraron los catorce puntos de los diputados americanos. Sin embargo, no deja de ser sugerente el hecho de que en enero de 1821 la corona emitió una circular para los virreinatos de México y Lima donde señalaba que, de conformidad con el sistema constitucional, era conveniente la separación de la superintendencia de hacienda pública

${ }^{39}$ Sesión del 11 de octubre de 1821 en Actas constitucionales mexicanas 1821-1824, introducción y notas de José Barragán Barragán, v. 1 (México: Universidad Nacional Autónoma de México, Instituto de Investigaciones Jurídicas, 1980) 33-36.

${ }^{40}$ Voz: "Memoria", en Canga Argüelles, Diccionario de hacienda..., v. 2, 237 y s.

${ }^{41}$ Sobre este documento, véase Manuel Chust, "Federalismo avant la lettre en las cortes hispanas, 1810-1821", en El establecimiento del federalismo en México, 1821-1827, coord. de Josefina Zoraida Vázquez (México: El Colegio de México, 2003), 105-107; Ivana Frasquet, Las caras del águila: del liberalismo gaditano a la república federal mexicana, 1820-1824 (Castelló de la Plana: Universitat Jaume I, 2008), 43-52.

${ }^{42}$ Sesión del 3 de noviembre de 1820, en "Congreso de los Diputados. Diario de sesiones. Serie histórica”, acceso el 9 de septiembre de 2019, https://app.congreso.es/est_sesiones/, 2057-2058. 
del cargo de virrey. Por otro lado, debo llamar la atención sobre otros aspectos de la circular, que en realidad era una instrucción. En apego al texto constitucional y leyes secundarias, la circular suprimía el juzgado y fuero de hacienda, así como "muchas de las facultades que estaban concedidas a los intendentes por la Ordenanza de Intendentes de 1786”.

En atención a esta afirmación, la circular continuaba con la definición de las competencias de los superintendentes y sus subordinados. En concreto, en su ejercicio y autoridad estos funcionarios debían hacer cumplir las leyes, resolver dudas y cuestiones conforme a ellas, sin interpretarlas ni alterarlas. En otras palabras, en su ejercicio de autoridad sólo intervendrían en lo meramente gubernativo y económico. Y la circular agrega:

[...] y de ningún modo en lo contencioso y judicial. Y para evitar las dudas que frecuentemente han solido ofrecerse sobre el verdadero sentido de estas palabras, declaro que: por contencioso se entiende todo lo que sea punto de derecho, que con razón se reduzca a pleito y haga forzosas las actuaciones judiciales. ${ }^{43}$

A unas semanas de consumada la independencia, en octubre de 1821 la consulta del ministro interino de hacienda pasó a la comisión correspondiente que pocos días después emitió su dictamen, el cual fue discutido en la Junta Provisional Gubernativa. La situación, decía el presidente de la comisión respectiva, se reducía a dos cuestiones. Primero, si era necesario generar el empleo de superintendente general de hacienda. Segundo, en el caso de que tal cargo fuere necesario, era preciso que se procediera a la sugerencia del ministro de hacienda, y retomada por la comisión, de asignar el trabajo "en lo económico" de la superintendencia a "las direcciones y demás ministros".

Fagoaga, uno de los miembros de la junta, propuso que se repitiera lo que se hizo en España y se estableciera un centro de unidad en el gobierno para la hacienda. Otro miembro, Rus, pedía que se desechara del todo la propuesta, en atención a que no era urgente y al artículo 14 de los Tratados de Córdoba, el cual sugería que no se adoptaran estas decisiones mientras no se reunieran las Cortes. El asunto se discutió en el pleno de la Junta y se decidió no establecer una superintendencia; en cuanto al segundo punto se sugirió que quedara pendiente en vista de que ya se había resuelto el

${ }^{43}$ Circular del rey del 29 de enero de 1821, enviada a la ciudad de México por el secretario del despacho de hacienda, Madrid, 15 de febrero de 1821, AGN, Indiferente virreinal, caja 5806, exp. 15. 
primero. El señor Espinosa, un tercer miembro de aquella Junta Provisional Gubernativa, sugirió que además de contar con los directores y demás ministros para las funciones económicas de la hacienda, se debía señalar expresamente que tales tareas competían también a las juntas provinciales de hacienda. El señor Gama le respondió que no era necesario por lo que Espinosa retiró su propuesta.

¿Por qué discutir el tema de la superintendencia si ésta había sido expresamente eliminada por las Cortes liberales de Cádiz y Madrid? Creo que la respuesta está en la proposición que hiciera el señor Espinosa - y que fue desechada- cuando sugirió que se incorporara a las diputaciones provinciales en el andamiaje administrativo-fiscal de la nueva nación. Como es bien sabido, las Cortes de Cádiz crearon la figura de las diputaciones provinciales y la consagraron en la constitución de 1812. Si regresamos al documento de la representación mexicana en las cortes de Madrid de noviembre de 1820 y al texto del decreto real de enero de 1821 , veremos que ambos documentos hablan de una superintendencia que comandara a todos los intendentes y administradores de rentas. Es decir, que se creara una estructura administrativa y fiscal independiente del resto de la administración del nuevo imperio.

La idea de un superintendente no era mala en tiempos en los que se requería de un personaje que permitiera al nuevo gobierno marcar su autoridad fiscal en los diversos espacios recién independizados de España. La presencia de un superintendente permitía también calibrar el nivel de tolerancia social hacia las cargas fiscales aplicadas desde la ciudad de México, más aún cuando se hacía necesario actualizar los cobros fiscales de frente a la construcción del nuevo país. ${ }^{44}$ El problema con un cargo como el de superintendente - jefe de intendentes y administradores de rentas- es que no era del todo compatible con la existencia de las diputaciones provinciales. En sí la superintendencia no debía presentar problema, pero me parece

${ }^{44}$ Desde el punto de vista práctico, el término superintendencia es bastante inasible, más aún porque no se conocen en detalle las discusiones de las comisiones de la Junta Provisional Gubernativa. Ante tal limitante la frase que ampara esta nota no es sino una especulación. La junta contemplaba la posibilidad de establecer el cargo de "superintendente de finanzas", tal y como se había definido a finales del siglo Xviı en España. Al respecto, véase Julio D. Muñoz Rodríguez, "El superintendente austriaco y el intendente borbónico. La evolución de un modelo de gestión de los recursos fiscales en la Monarquía hispánica”, en Las monarquías española y francesa (siglos XVI-XVIII) ¿Dos modelos políticos?, coord. de Anne Dubet y José Javier Ruíz Ibáñez (Madrid: Casa de Velázquez, 2010), § 4, acceso el 15 de septiembre de 2019, http://books.openedition.org/cvz/970. 
que algunos miembros de la Junta Provisional Gubernativa temían que se generara otra estructura paralela además de la que ya existía, que era la militar. Y con todo y que el imperio mexicano se pensaba como un régimen fiscalmente centralista, ${ }^{45}$ a todos convenía no hacer las cosas más complicadas de lo que ya eran.

Por otro lado, la Junta Provisional Gubernativa no adoptó la figura del superintendente porque este cargo conllevaba el poder de gastar el recurso público, lo que se dificultaba enormemente en tiempos en que se debía pagar al ejército de manera inmediata. En julio de 1821 Novella instruía a la casa de moneda de México que proveyera de recursos a la tesorería "para sus atenciones"; en octubre siguiente Iturbide instruía a la misma ceca de la capital que entregara recursos a la tesorería para pagos a los oficiales. ${ }^{46}$ Crear de buenas a primeras una superintendencia de hacienda encargada de acopiar, por vía de los intendentes, los recursos de las cajas nacionales y administraciones de rentas provinciales significaba crear un cargo excesivamente poderoso y por lo tanto inconveniente para el cuerpo militar trigarante, toda vez que éste quedaría sujeto a las decisiones financieras del superintendente.

Fue así que en México independiente, en lugar de una superintendencia y de una dirección general de hacienda pública, esta última creación de las Cortes, ${ }^{47}$ se creó un ministerio de hacienda. Tal decisión formó parte de una de las primeras disposiciones de la regencia; en México habría cuatro secretarías de Estado y del despacho universal: relaciones interiores y exteriores; justicia y negocios eclesiásticos; hacienda y guerra (marina estaba incluida en esta última). La organización de las secretarías estaba

${ }^{45}$ El término refiere a que las contribuciones eran determinadas, aplicadas, contabilizadas y asignadas en la ciudad de México. Este tipo de centralismo peleaba con la realidad, toda vez que, además de las diputaciones provinciales que buscaban tener sus propias prerrogativas financieras, también estaban los militares que contaban con una estructura paralela al gobierno imperial y a las diputaciones provinciales. Armar un andamio administrativo-fiscal con alto poder sobre la sociedad, como era el caso de los superintendentes/intendentes y administradores de rentas, era a todas luces inconveniente. Véase arriba la nota 8 .

${ }^{46}$ Novella a Lardizabal, México, 11 de julio de 1821, AGN, Indiferente virreinal, Casa de Moneda, caja 7207, exp. 068; Firma ilegible al generalísimo de mar y tierra, México, 8 de octubre de 1821, AGN, Indiferente de guerra, caja 3045, exp. 10.

${ }^{47}$ Decreto del 12 de abril de 1813, en Colección de los decretos y órdenes que han expedido las cortes generales y extraordinarias desde 24 de febrero de 1813 hasta 14 de setiembre del mismo año, en que terminaron sus sesiones, v. 4 (Madrid: Imprenta Nacional, 1820), 48-49. 
conformada por oficiales: oficial mayor 10., oficial mayor 20., oficial a secas y así hasta el portero, archivero, etcétera. ${ }^{48}$

En cuanto a la administración fiscal de las provincias, uno de los miembros de la junta provisional hizo una pregunta bastante sensata: ¿quién tenía autoridad para cobrar impuestos? La respuesta era "la diputación provincial en donde las hubiera”. Una pregunta más sutil: ¿quién perseguía a los que no cumplían con sus obligaciones fiscales? La respuesta del señor Gama fue que se mantuviera el statu quo del tiempo de la dominación española. En atención a un decreto publicado apenas cuatro meses antes de la consumación de la independencia, tal situación era que

[...] hasta tanto se establezca el arreglo general de hacienda se autorice provisionalmente a los intendentes para que en materia de contribuciones y toda clase de impuestos, en cuanto a su cobranza, puedan cobrar por sí, y sin necesidad de implorar el auxilio del poder judicial ni otra autoridad. ${ }^{49}$

Lo que significaba que los intendentes se ocuparían del cobro de los impuestos, pero también de labores de carácter jurisdiccional. La revisión de algunas actas de las diputaciones provinciales muestra que, aunque sin aludir al decreto anterior, en la práctica los jueces no fueron dotados de su jurisdicción. Por ejemplo, uno de los aguadores de la ciudad de Zacatecas desatendió una multa impuesta por el jefe político alegando que por el mismo asunto tenía un juicio pendiente en el juzgado de letras. El juez manifestó su queja señalando que la diputación provincial se entrometía en asuntos que no eran de su jurisdicción. La diputación respondió con un extrañamiento al magistrado por entrometerse en las determinaciones gubernativas. ${ }^{50}$

48 "Reglamento para el gobierno interior y exterior de las secretarías de estado y del despacho universal." A este decreto se le conoce como "Disposición 255 del 8 de noviembre de 1821", en Manuel Dublán y José María Lozano, Legislación mexicana o colección completa de las disposiciones legislativas expedidas desde la independencia de la República ordenada, v. 1 (México: Imprenta del Comercio, 1876), 554-559.

49 "Concediendo a los intendentes ciertas facultades para la cobranza de contribuciones e impuestos. Disposición 238: decreto del 12 de mayo de 1821”, en Dublán y Lozano, Legislación mexicana..., v. 1, 543-544.

${ }^{50}$ Acta del 10 de abril de 1823, en La Diputación Provincial de Zacatecas. Actas de sesiones, 1822-1823, ed., estudio introductorio y sumario de Beatriz Rojas Nieto (México: Instituto de Investigaciones Dr. José María Luis Mora/Gobierno del Estado de Zacatecas, 2003), 125-128. 
Otra de las decisiones importantes que debía tomar la junta provisional era el trabajo del secretario y sus subordinados. Como lo dice el nombre de su puesto, el secretario se hacía cargo del despacho de hacienda, lo que significaba resumir y concluir los asuntos de su competencia. También era su tarea proponer a la regencia las reformas necesarias en materia financiera y escuchaba las propuestas de personas interesadas en el tema de su competencia; se entiende que también comunicaba al público las decisiones adoptadas por la regencia.

El secretario solamente instruía al oficial mayor primero. ${ }^{51}$ Éste era quien se encargaba de que los asuntos se distribuyeran entre el resto de los oficiales del ministerio, así como de hacer recomendaciones que el ministro después llevaría al acuerdo con la regencia. La tarea más importante del oficial primero era revisar las solicitudes de gasto y pasarlas al ministro para que éste diera su visto bueno y para que sólo así pudieran ser admitidas en la tesorería general de la nación. Por su parte, cabe añadir que esta última oficina al parecer se mantuvo de alguna forma independiente del ministerio de hacienda. Prueba de esto son las órdenes ya referidas de Novella e Iturbide en julio y octubre de 1821, respectivamente, así como el hecho de que los dos oficiales nacionales (tesorero y contador) de los últimos meses de la dominación española permanecieron hasta varios meses después de consumada la independencia. ${ }^{2}$

${ }^{51} \mathrm{Al}$ parecer no se siguió la idea de crear una dirección general de hacienda, sino más bien la idea de una oficialía mayor lo que me parece una solución práctica, pues tal oficina no requiere de un reglamento y permite al secretario del despacho tener un control mayor sobre las tareas del ministerio. Al respecto Veytia apunta que uno de los grandes inconvenientes de las direcciones generales es que tienden a adquirir demasiadas atribuciones, lo que obstaculiza la comunicación frecuente y oportuna con el secretario de Estado. M. R. Veytia, "Naturaleza, límites y organización general de la administración", Revista de Administración Pública. Edición especial en memoria del maestro y primer presidente del INAP: Gabino Fraga. La concepción de la administración pública a través del derecho administrativo mexicano. Pasado y presente, n. 1982 (noviembre 1982): 195-209. Por otro lado, no se debe descartar que se utilizó el término oficial mayor porque una dirección general requiere de más experiencia, lo que explica en parte por qué esta oficina de hacienda no se creó sino hasta 1831.

52 Antonio Batres y Adrián Ximénez al virrey [sic] Novella, México, 12 de julio de 1821, AGN, Indiferente virreinal, Casa de Moneda, caja 5207, exp. 068; Antonio Batres y Adrían Ximénez al superintendente de hacienda pública, México, 6 de octubre de 1821, AGN, Indiferente de guerra, caja 3045, exp. 10; "Estado que manifiesta el ingreso y egreso de caudales que esta Tesorería General de Ejército y Hacienda Pública ha tenido desde el día 12 de enero al 30 de abril, ambos inclusive, del año presente", en Gaceta del Gobierno Imperial de México, México, 31 de enero de 1822. 
A inicios de 1822 la tesorería experimentó una primera modificación de importancia. Como los recursos eran escasísimos, se determinaron las medidas de siempre: congelamiento de plazas, suspensión de pensiones y jubilaciones y la prohibición total de gastos sin autorización expresa del ministro de hacienda. Días después de que quedara instalado el congreso constituyente a finales de febrero de 1822 se ordenó que tanto la tesorería general como las cajas foráneas debían enviar al ministro de hacienda informes en donde se consignaran los ingresos, los gastos y los sobrantes (netos de los "gastos de dotación"). ${ }^{53}$ Por su parte, las tesorerías particulares de rentas (tabaco, pólvora, papel sellado, etcétera) debían remitir a la caja general un informe sobre sus sobrantes "después de gastos de dotación". Los informes servían para que el ministro tuviera una idea de las existencias y así asignarlas "según el servicio de la nación". Los sobrantes de las cajas en la ciudad de México eran para completar los pagos de la lista civil y militar de la capital. Todas estas instrucciones repetían las que se venían emitiendo desde tiempos coloniales; la reforma más importante que experimentó la tesorería con el decreto del 11 de marzo de 1822 fue la eliminación de la tesorería y contaduría del ejército. ${ }^{54}$

Ésta y otras reformas, como confirmar en sus cargos a todo el cuerpo de funcionarios de gobierno y otros que resultaban de cambios en la administración tributaria, se llevaron a cabo con posterioridad al establecimiento del congreso constituyente.

Las propuestas iniciales de México eran adecuadas para el establecimiento de la administración pública de una nueva nación que era independiente de cualquier otra y que vislumbraba un futuro promisorio. Pero en atención a los decretos de marzo de 1822 que emitían órdenes concretas, surge la pregunta ¿̇a quién iban destinados? O de otra manera ¿qué ámbito administrativo del pasado colonial estaba considerando el congreso?, ¿en dónde estaban los empleados civiles y militares que refieren los decretos? Para ello es necesario describir la administración pública en las provincias.

${ }^{53}$ Son los gastos solicitados por cada secretario del despacho al de Hacienda. Hoy día se denominan "gastos presupuestados". Anne Dubet, La hacienda real de la nueva planta (17131726), entre fraude y buen gobierno. El caso Verdes Montenegro (Madrid: Fondo de Cultura Económica de España, 2015), 127-129.

54 "Prohibición a los que manejan caudales de la nación...", Decreto del 11 de marzo de 1822, en Mariano Galván Rivera, Francisco del Moral e Isidro Rafael Gondra, Colección de órdenes y decretos de la Soberana Junta Provisional Gubernativa y soberanos congresos generales de la nación mexicana, v. 2 (México: Imprenta de Galván a cargo de M. Arévalo, 1829-1840), 6-7. 
El gobierno de Iturbide: la administración provincial

Tanto la Junta Provisional Gubernativa como el primer Congreso Constituyente estaban conscientes de que tenían poco control sobre las figuras fiscales de las regiones. Más aún, la tesorería en la ciudad de México estaba prácticamente desdibujada dentro de las provincias. Un ejemplo elocuente de esta situación se puede utilizar para probar esta aseveración. Según lo estipuló la Junta Provisional Gubernativa, las diputaciones provinciales tenían que idear las contribuciones - que cobrarían los ayuntamientosdestinadas al pago de sueldo y viáticos de los diputados del primer congreso constituyente a inicios de $1822 .{ }^{55}$ Por esos días, y en atención a lo estipulado por la junta gubernativa, la Dirección General del Tabaco en la ciudad de México comunicó al factor de este producto en Durango que no entregara recurso alguno para las atenciones de la provincia sin previa orden del "señor generalísimo". El factor preguntó a la diputación provincial si esta orden incluía la provisión de recursos para la asistencia de los diputados al congreso, pues él consideraba que era de la mayor trascendencia. La respuesta de la diputación acordó que el factor obedeciera las instrucciones de este cuerpo y que avisara a la dirección general sobre esta decisión. ${ }^{56}$ Esto es, la factoría de tabaco de Durango entregaría recursos para el financiamiento de los diputados de aquella provincia. Varias semanas después el ministerio de hacienda pedía a la diputación que se reintegraran los recursos, a lo cual la junta provincial accedió. ${ }^{57}$ Para agosto de 1822 desde la ciudad de México se conminaba al intendente de Durango para que cobrara estos dineros a la diputación provincial. La respuesta de este cuerpo fue la instrucción al intendente de que, ante la falta de recursos, buscara la venta de una hacienda de la ex-Inquisición para auxiliar cuanto antes a los diputados..$^{58}$

${ }^{55}$ María José Garrido Asperó, “¿Quién paga los gastos de la representación política? Las dietas de los diputados de la provincia de México en el primer Congreso Constituyente mexicano", Secuencia, n. 87 (enero-abril 2013): 31-48.

${ }^{56}$ Acta del 8 de febrero de 1822, en La Diputación Provincial de Provincias Internas de Occidente (Nueva Vizcaya y Durango). Actas de sesiones, 1821-1823, estudio introductorio de César Navarro Gallegos (México: Instituto de Investigaciones Dr. José María Luis Mora, 2006), 122-123. Gaceta Extraordinaria del Gobierno Imperial de México, México, 5 de marzo de 1823.

57 Acta del 10 de abril de 1822, en La Diputación Provincial de las Provincias Internas de Occidente..., 160-163.

58 Acta del 2 de agosto de 1822, en La Diputación Provincial de las Provincias Internas de Occidente..., 232-235. Aquí se debe señalar que, de manera no legislada, las propiedades de 
Dos aspectos se perciben en este ejemplo. Por una parte, a pesar de que la ley exigía que la diputación provincial se hiciera de recursos propios para el pago de los viáticos y dietas de los diputados, vemos a una corporación provincial que no contaba con recursos para este menester. Por ello debía recurrir a los recursos de las oficinas locales del gobierno asentado en la ciudad de México. En segundo lugar, vemos a un intendente dividido entre las instrucciones recibidas de la capital del imperio y las tareas asignadas por la diputación provincial. Y es que, ya sin funciones judiciales que eran desempeñadas por los subdelegados, el cargo de intendente se fue haciendo paulatinamente prescindible y con poco efecto sobre la administración financiera de las provincias. Al paso de los meses éstas podían continuar trabajando con los oficiales o ministros de hacienda y los empleados de la aduana nacional encargados de las rentas de alcabalas y tabaco. Al respecto, valga el ejemplo de la diputación de Durango que, ante la falta de recursos para financiar las dietas y viáticos de los diputados del congreso restaurado en 1823, procedió a aplicar un sobreprecio al papel para la elaboración de cigarros. ${ }^{59}$ Otro caso muestra que la diputación provincial se recargó en la administración de los ayuntamientos. En Guanajuato las cargas para el pago de las dietas de los diputados fueron una contribución directa sobre propiedad rústica y sobre el consumo de carnes. La colecta de ambos impuestos fue tarea de los ayuntamientos de la provincia. ${ }^{60}$

Se concluye que, al menos en el caso de Durango, la diputación provincial no era tan fiscalmente autónoma como sospechábamos, pero tampoco la vemos totalmente dependiente de los recursos recibidos de la capital imperial. Una orientación más financieramente autónoma la veremos después del verano de 1823, cuando el congreso restaurado otorgará a las provincias el cobro y la distribución de las contribuciones directas. A decir de Serrano Ortega, esta medida respondió a la necesidad de aquel congreso

temporalidades y otros bienes raíces eran propiedad del gobierno imperial y no de las diputaciones provinciales.

${ }^{59}$ Actas del 10 y 14 de mayo y 28 de junio de 1823, en La Diputación Provincial de las Provincias Internas de Occidente..., 387-389, 390-393, 416-418.

${ }^{60}$ Actas del 3 de mayo y 10 de septiembre de 1822, en La Diputación Provincial de Guanajuato. Actas de sesiones, 1822-1824, estudio introductorio de José Antonio Serrano Ortega (México: Instituto de Investigaciones Dr. José María Luis Mora/El Colegio de Michoacán, 2016), 73-75, 120-122. 
de congraciarse con las élites regionales en aquellos momentos en los que el antiguo virreinato corría el peligro de desintegrarse. ${ }^{61}$

Es pertinente comentar sobre las oficinas que guardaban, contabilizaban y distribuían los recursos que en este periodo eran considerados del gobierno general. Casi invisibles, desde sus orígenes remotos los tesoreros y los contadores de las cajas del erario novohispano y mexicano han sido ignorados por la historiografía económica, no obstante que ellos firmaban libros, cortes de caja y otros documentos. En el último periodo de este cargo - que fue eliminado a fines de 1824 con la creación de las comisarías generales- los funcionarios que anteriormente se conocían como "oficiales reales" habían adquirido la denominación de "ministros nacionales" (también "ministros de hacienda pública"). ${ }^{62}$ El cambio no era, empero, nada más de nombre, pues mientras que en tiempos coloniales los oficiales reales tenían funciones consultivas, contenciosas y económicas, ${ }^{63}$ después de 1820 los ministros de la hacienda pública - y para tal efecto también los intendentes- sólo tenían atribuciones de carácter económico. ${ }^{64}$ En todo caso, los ministros nacionales en las provincias debieron haber enfrentado enormes dificultades para el cobro de contribuciones en vista de lo ya señalado sobre la resistencia de la población al pago de impuestos. Los ayuntamientos en cambio contaban con diversos recursos propios que permitían

${ }^{61}$ José Antonio Serrano Ortega, "Liberalismo y contribuciones directas en México, 1810-1835”, en La trascendencia del liberalismo doceañista en España y en América, coord. de Manuel Chust Calero e Ivana Frasquet Miguel (Valencia: Generalitat Valenciana, Conselleria de Cultura, Educació i Esport, 2004), 201. En el mismo tenor fue la orden del gobierno del 24 de mayo de 1823 en la que instruyó a las diputaciones provinciales a que, así como había hecho la diputación de México, formaran un plan de propios y arbitrios. Acta del 5 de junio de 1823, en La Diputación Provincial de San Luis Potosí. Actas de sesiones, 1821-1824, estudio introductorio de María Isabel Monroy Castillo, v. 1 (México: Instituto de Investigaciones Dr. José María Luis Mora/El Colegio de San Luis, 2012), 483-485.

${ }^{62}$ Por ejemplo, véase Licenciado José Ildefonso Díaz de León, presidente, y Josef Macario Casamadrid, secretario, a la Excelentísima Diputación Provincial, San Luis Potosí, 30 de abril de 1823, documento del Acta del 5 de mayo de 1823, en La Diputación Provincial de San Luis Potosí..., v. 1, 300-410.

${ }^{63}$ Sobre éstas y otras funciones de los oficiales reales en tiempos coloniales, véase José Luis Galván Hernández, "Al mejor servicio del rey: la Junta Superior de Real Hacienda en Nueva España, 1786-1821" (tesis de licenciatura, Instituto de Investigaciones Dr. José María Luis Mora, 2017), passim.

${ }^{64}$ Véase arriba la nota 43. "Tercera junta preparatoria para el soberano congreso constituyente, verificada el día 4 de noviembre de 1823”, en Águila Mexicana, México, 5 de noviembre de 1823. 
hacer frente a los gastos más urgentes. Por ejemplo, a mediados de abril de 1823 el ayuntamiento de San Luis Potosí se vio en la necesidad urgente de proporcionar cuartel al regimiento número 12 de la comandancia general de la provincia. Ante la imperiosa necesidad, con la autorización de la diputación provincial, el ayuntamiento tomó fondos destinados a las casas consistoriales cuando en realidad el gasto debió asumirse por los "señores ministros de hacienda pública". ${ }^{65}$ Y así, una y otra vez, en aquellos meses las diputaciones provinciales consultaban a los ministros de la hacienda pública si tenían recursos para las urgencias que presentaba, particularmente, el ejército. Es un tema que requiere muchas más evidencias, pero al parecer muchos gastos fueron, como en el ejemplo expuesto, asumidos por los ayuntamientos aun y cuando las diputaciones provinciales (o al menos la de San Luis Potosí) habían manifestado su falta de "autoridad para permitir gasto alguno en objetos que est[é]n fuera del conocimiento e inspección de [este] cuerpo". ${ }^{66}$

\section{Las intendencias federales}

Así como los intendentes llegaron en 1786 a reformar un sistema administrativo que ya no daba más, así en 1824 los intendentes mostraban su disfuncionalidad en el nuevo orden de cosas. Pero en realidad no es que el cargo en sí fuera problemático, pues los intendentes eran comisarios; es decir, tenían tareas específicas y claramente delineadas en una ordenanza. ${ }^{67}$ Tal y como fueron creados, los intendentes y sus cuatro causas son los que ya no tenían razón de ser en un mundo liberal en el que al menos desde el

${ }^{65}$ Manuel Sánchez, presidente, y Josef Macario Casamadrid, secretario, a la excelentísima diputación provincial, 16 de abril de 1823, documento del acta del 21 de abril de 1823, en La Diputación Provincial de San Luis Potosí..., v. 1, 326-375.

${ }^{66}$ Licenciado José Ildefonso Díaz de León, presidente, y Josef Macario Casamadrid, secretario, a la Excelentísima Diputación Provincial, San Luis Potosí, 30 de abril de 1823, documento del Acta del 5 de mayo de 1823, en La Diputación Provincial de San Luis Potosí..., v. $1,300-410$.

${ }^{67} \mathrm{Al}$ respecto, véase Horst Pietschmann, Las reformas borbónicas y el sistema de intendencias en Nueva España: un estudio político administrativo (México: Fondo de Cultura Económica, 1996). Sobre la labor comisarial de los intendentes, véase Omar Guerrero Orozco, "Estudio introductorio", en Principios de administración pública, Charles-Jean Bonnin, comp. y estudio introductorio de Omar Guerrero (México: Fondo de Cultura Económica, 2004), 64-71. 
punto de vista legal prevalecía un sistema de pesos y contrapesos por la presencia de tres poderes independientes entre sí. ${ }^{68}$

Como sugiero en la primera parte de este artículo, tanto con la promulgación de la Constitución de 1812 como por la circular de enero de 1821, los intendentes vieron reducidas drásticamente sus funciones. Ya no tenían poder judicial, ni de guerra y probablemente tampoco de policía; lo único que les quedaba era la competencia en cuestiones económicas. El problema surgió de que, a la vez que se mantuvieron los intendentes, la constitución también creó las diputaciones provinciales. Según Benson, no es fácil determinar la relación entre el intendente y la diputación provincial; era el jefe de esta última en el caso de la ausencia del jefe político y no tenía voto, como tampoco lo tenía este último. En otras palabras y para reducir el poder de la monarquía en las provincias "no tenían información en cuestiones discutidas por la diputación provincial pero debían adoptar sus decisiones en asuntos que tuvieran que ver con su autoridad". ${ }^{69}$

En 1823, con la restauración del congreso anteriormente disuelto por Iturbide y la abdicación de este último, se suscitó la discusión sobre quién mandaba en el país. Nunca se dio una respuesta, pero el debate hizo evidente que México se había fraccionado en provincias, cada una de las cuales asumió control dentro de sus fronteras. En la mayoría de las provincias el jefe político se convertía en el poder ejecutivo provincial y la diputación (junta en algunos lados) asumió funciones legislativas de gobierno. A partir del 29 de marzo de 1823 y hasta la promulgación de la Constitución en octubre de 1824, la mayoría de las provincias/intendencias se gobernaron de manera independiente y solamente obedecieron las leyes de los gobiernos nacionales cuando así les convenía.

Es precisamente en una parte de este periodo - los meses entre febrero y hasta septiembre de 1824-que en México existieron los intendentes federales. En mi opinión, se trataba de un cargo ya muy distorsionado respecto a su espíritu inicial, excepto en el caso que tiene que ver con las finanzas gubernamentales y con su administración. Más aún, la distorsión surgía por el hecho de que en aquellos meses de 1824 no respondían ya más a los dictados de una diputación provincial, sino que obedecían en buena parte a los designios del gobernador o al gobernador teniente del

${ }^{68}$ De nuevo hago referencia a la nota 43 de más arriba en donde se refiere la circular de enero de 1821 que deja clara la delimitación de funciones de los intendentes.

${ }^{69}$ Nettie Lee Benson, The Provincial Deputation in Mexico. Harbinger of Provincial Autonomy, Independence, and Federalism (Austin: University of Texas Press, 1992), cap. 1. 
estado. Aquí se debe señalar que para cuando se promulgó el Acta de la Federación Mexicana (que fue la base de la constitución de octubre de ese año) ya se consideraban estados de la federación a Guanajuato, Sonora/ Sinaloa, Coahuila/Texas/Nuevo León, Chihuahua/Durango/Nuevo México, estado de México, Michoacán, Oaxaca, Puebla, Tlaxcala, Querétaro, San Luis Potosí, Tamaulipas, Tabasco, Veracruz, Jalisco, Yucatán y Zacatecas. ${ }^{70}$ Me imagino que no todos tenían intendente.

Los intendentes federales existieron y las fuentes los mencionan, aunque no con ese nombre. En la sesión del congreso de Puebla del 30 de marzo de ese año se propuso que el intendente presidiera una junta para la evaluación del papel moneda presentado para su amortización en las oficinas de hacienda pública del estado. Además, se proponía que el intendente fuera el encargado de fincar responsabilidades sobre los jefes de hacienda que recibieran en pago papeles que resultaran falsos. Este asunto aparentemente no fue aprobado, pues el papel moneda era una cuestión nacional y la propuesta del congreso poblano se circunscribía al territorio de la entidad. ${ }^{71}$

Al parecer, los intendentes eran, por otro lado, útiles para la administración fiscal del gobierno general en 1824. Tal utilidad surgía de un hecho incontestable: los intendentes tenían la memoria de lo que había sucedido en los años previos. A mediados de abril de ese año el ministro de hacienda Arrillaga instruía al intendente de San Luis Potosí que reactivara una convocatoria para la venta de la exhacienda de Solís, que en 1822 había sido cedida como préstamo por parte de los carmelitas de aquella jurisdicción. ${ }^{72}$

Es muy probable que en aquellos meses de 1824 no estuviera muy clara la posición legal de los intendentes. En la sesión del congreso general del 13 de enero se leyó una exposición del exdiputado Manuel Jiménez de Bailo en la que preguntaba si le correspondía ser intendente de provincia, tal y como se le había otorgado en julio de 1821. Aunque no tengo la respuesta de parte de la comisión de justicia del congreso, es casi seguro que se le denegara porque el nombramiento no había sido otorgado por gobierno independiente alguno. Aun así, la duda muestra que el cargo no tenía ya mucho lugar en las estructuras de mando previas a la reforma administrativa aplicada por el congreso federal a finales de ese año. En los últimos

${ }^{70}$ Hira de Gortari, "La organización política territorial de la Nueva España a la primera república federal, 1786-1827”, en El establecimiento del federalismo en México, 1821-1827, coord. de Josefina Zoraida Vázquez (México: El Colegio de México, 2003), 39-76.

71 "México 12 de abril”, El Sol, México, 12 de abril de 1824.

72 “Ministerio de hacienda”, El Sol, México, 24 de abril de 1824. 
días de enero el propio secretario de hacienda solicitaba al congreso que resolviera una controversia que se había suscitado entre el intendente de Veracruz y el ayuntamiento de Alvarado, pues éste se negó a entregar casas particulares que pretendía utilizar el intendente para almacenes "donde depositar y custodiar los cargamentos que allí se desembarcan”. Este asunto revela un problema de competencias entre los ayuntamientos y los mandos de los estados (gobernador, secretario de gobierno, intendente, etcétera) al momento que desaparecieron las diputaciones provinciales. Por cierto, días después la comisión resolvió sobre esta controversia y escuetamente señaló: "que se vuelva este expediente al gobierno para que obre conforme a las leyes". No se trataba de señalar quién mandaba encima de quién, pues lo que la comisión quiso decir es que un juez resolviera el asunto. ${ }^{73}$

Las controversias con otro poder elegido las resolvía un juez, no así las que tenían que ver con la propia administración estatal que paulatinamente iba estableciendo sus jerarquías. Y aquí sí las instancias gubernativas ya no obedecían más al intendente. En la discusión sobre los bienes de los hospitalarios exclaustrados, el congreso constituyente del estado de México fue explícito al indicar que quien entregaría la documentación sobre éstos sería el intendente, pero que lo haría solamente por conducto del gobernador, lo que indica sin lugar a dudas que el intendente era sólo un "acopiador de papeles” para el gobernador y el congreso; en este ejemplo parecería incluso que el congreso no tenía muy claro qué hacer con los antiguos intendentes. ${ }^{74}$ Por su parte, en el estado de Puebla aparentemente se tenía uso claro de estos funcionarios, toda vez que sus autoridades se arrogaban la atribución de nombrar a su intendente. ${ }^{75}$

Pero eso era en los estados de México y Puebla, mas no todas las otras entidades operaban uniformemente. En Guadalajara, por ejemplo, la diputación

${ }^{73}$ Acta del congreso general del 21 de abril de 1824, en Águila Mexicana, México, 22 de abril de 1824. Véase también "Instrucción para los ayuntamientos constitucionales, juntas provinciales y jefes políticos superiores” [del 23 de junio de 1813], en Juan E. Hernández y Dávalos, Colección de documentos para la historia de la guerra de independencia de México de 1808 a 1821, v. 5 (México: José María Sandoval Impresor, 1877-1881), documento n. 166.

${ }^{74}$ Acta del congreso constituyente del estado de México, 10 de mayo de 1824, Águila Mexicana, México, 13 de mayo de 1824.

75 Se trata de la representación del anterior intendente de Guanajuato, Fernando Pérez Marañón, quien en fechas anteriores había sido designado para ocupar la intendencia en Puebla. En respuesta, el congreso de ese estado rehusó admitirlo "por creer que le corresponde el nombramiento de aquel empleo". Acta del congreso general del 12 de junio de 1824, El Sol, México, 15 de junio de 1824. 
provincial había determinado en junio del año anterior que quedaban vigentes todos los empleos asignados hasta esa fecha. Por tal motivo, el gobernador daba instrucciones al intendente para que pagara los sueldos y otros gastos del estado. ${ }^{76}$ Ante tal testimonio, de cualquier forma cabe preguntar que si la tesorería de Guadalajara contaba con "ministros principales de hacienda pública", 77 ¿qué papel desempeñaba el intendente? En un remitido desde Acapulco, el periódico Águila Mexicana publicó una carta de un Manuel de Jesús Fernández en donde éste relató que, por una denuncia a contrabandistas, él fue arrestado en su casa en espera de "la resolución del intendente" que, "con los demás jefes de hacienda pública”, habían visto con indiferencia su caso. ${ }^{78} \mathrm{Si}$ bien es tan sólo un ejemplo, podemos ver que el intendente en este caso actuaba como autoridad que debía esperar la resolución de un juez.

Como ya sabemos, el proyecto de clasificación de rentas entre los estados y la federación se presentó ante el segundo constituyente en algún día de inicios de mayo de $1824 .{ }^{79} \mathrm{El} 29$ de ese mes, la comisión del sistema

${ }^{76}$ Luis Quintanar a Anastasio Bustamante, Guadalajara, 10 de marzo de 1824, Águila Mexicana, México, 16 de mayo de 1824.

77 Acta de la diputación provincial de Nueva Galicia, 19 de septiembre de 1822, en La Diputación Provincial de Nueva Galicia. Actas de sesiones, 1820-1822, estudio introductorio de Jaime Olveda, ed. y sumario de Beatriz Rojas (México: Instituto de Investigaciones Dr. José María Luis Mora/Universidad de Guadalajara, 2004), 212-218.

78 "Remitido", Águila Mexicana, México, 14 de mayo de 1824.

${ }^{79}$ Durante el debate sobre las atribuciones del supremo poder ejecutivo, días antes de que se promulgara el acta constitutiva de la federación, Valentín Gómez Farías, diputado por el segundo congreso constituyente, había exigido que la comisión de hacienda, en unión con el secretario del ramo, procedieran a formar un sistema general de rentas que estuviera de acuerdo con el tipo de gobierno que iba a adoptar la república. Acta del congreso general (concluye) del 23 de enero de 1824, Águila Mexicana, México, 25 de enero de 1824. A principios de febrero de 1824 el diputado por Puebla, José Mariano Marín, propuso ante la cámara que en el tiempo perentorio de quince días la comisión de hacienda, de la que él formaba parte, entregara sus resultados sobre los ramos que se reservarían a la federación y los que quedarían a favor de los estados. Más importante aún, Marín preguntaba sobre la manera como se iban a administrar los impuestos federales en los estados. Acta del congreso general del 6 de febrero de 1824, Águila Mexicana, México, 7 de febrero de 1824. Días después, el secretario de hacienda apuraba al congreso para que designara nominalmente las rentas generales que correspondían a la federación. Acta del congreso general del 10 de febrero de 1824, Águila Mexicana, México, 11 de febrero de 1824. Aunque el oficio se envió a la comisión de sistema de hacienda, el mismo mostraba la necesidad de arreglar las cosas lo más pronto posible, toda vez que se estaban deteniendo algunos aspectos importantes de las tareas gubernamentales; por ejemplo, el 4 de marzo se leyó por vez primera el dictamen de la comisión de hacienda sobre que se suspendiera la provisión de vacantes del tribunal de la contaduría 
de hacienda expuso su dictamen ante el pleno del congreso y al día siguiente comenzó la discusión en lo general ${ }^{80}$ La primera intervención fue la del diputado por Jalisco y confederalista radical, Juan Cayetano Portugal. Discutía sobre la complicación que se pretendía en la administración financiera de la república, toda vez que el proyecto proponía una organización estatal y otra federal; esta última pretendía introducir empleados federales adentro de los estados. Y para ejemplificar la complicación que esto acarrearía, Portugal mencionaba las diferencias y contestaciones que por esos meses tenían el gobernador de Jalisco, el intendente en el estado y el ministro de hacienda sobre la repartición de comisos. ${ }^{81}$ De manera que la presencia de los intendentes en el interior de los estados en los meses posteriores a febrero de 1824 se constituyó en una fuente de conflictos sobre la manera como se iban a distribuir los beneficios y las cargas fiscales de la nación. Siquiera de paso, Juan Cayetano Portugal llamó la atención al problema de la presencia de los intendentes en los flamantes estados de la república.

Varias semanas después, se intensificó este llamado de atención ante la lectura de un dictamen sobre un proyecto enviado por el intendente de México a finales de marzo anterior: la propuesta llevaba por nombre "Plan de organización de la intendencia y hacienda pública del estado de México". No conozco el plan original ni tampoco el dictamen, pero sí conozco la discusión sobre el mismo que se dio en el congreso. Los diputados Paz, Gómez Farías y Godoy impugnaron el dictamen porque dijeron que era necesario esperar a ver qué salía de la nueva organización de la hacienda; de otra forma resultaría defectuoso "si se hace parcialmente o se crean empleados que después resulten superfluos y acaso pretendan la pensión de cesantes”. En posición opuesta estuvieron los diputados Zavala, Bustamante y González Angulo, quienes proponían la aprobación del dictamen porque tales empleados eran necesarios en esos momentos y se les debía pagar "mientras se organiza el sistema general de hacienda". Godoy reclamaba que su intención no era que se les dejara de pagar, sino que no se

mayor "hasta el arreglo de la hacienda". Acta del congreso general del 3 de marzo de 1824, Águila Mexicana, México, 4 de marzo de 1824.

${ }^{80}$ El estudio más acabado de estas discusiones se encuentra en Hernández Jaimes, La formación de la hacienda pública mexicana..., 140 y s.

${ }^{81}$ Acta del congreso general del 29 de mayo de 1824, Águila Mexicana, México, 30 de mayo de 1824. Lo que Portugal alegaba era que los estados debían tener control absoluto sobre sus rentas y la presencia de un funcionario federal en los estados, a la usanza de lo que habían sido los intendentes, iba en contra de su independencia. Hernández Jaimes, La formación de la hacienda pública mexicana..., 156-157. 
aprobasen estas posiciones de manera permanente. A fin de cuentas, no se llegó a nada, sin duda porque el cambio administrativo (hacia la creación de las oficinas federales) ya estaba en marcha; el dictamen se desechó, no se votó y no se devolvió a la comisión.

Lo que vemos es un último intento por parte de los intendentes de salvar del olvido un cargo que había sido muy útil a la administración financiera de la monarquía española. Sin embargo, y muestra de que ya tenían la partida perdida, su plan fue presentado muy tarde, probablemente con ayuda de la comisión de hacienda que tardó más de tres meses en someterlo al pleno parlamentario.

Los intendentes continuaron en sus puestos; sin embargo, las fuentes muestran que hacia finales de 1824 sólo tuvieron presencia en detalles pequeños como reclamos de sueldos y pensiones. ${ }^{82} \mathrm{~A}$ mediados de noviembre se presentó un hecho simbólico. En el congreso constituyente del estado de México - que para esas fechas celebraba sus sesiones en la capital del estado que era, también, la capital de la república- se leyó una carta del gobernador en la que ordenaba que el intendente desocupara el espacio que habitaba en las casas consistoriales de la ciudad o que pagara los arrendamientos. ${ }^{83}$ Un mero trámite, pequeño, pero significativo de que los intendentes de lo que fue Nueva España y luego México habían llegado a su fin.

Reflexiones finales

El trabajo aquí presentado aporta pocas respuestas y postula múltiples preguntas de corte administrativo. Se me hace evidente la debilidad de Apodaca hacia finales de su mandato. Aunque la tardanza en la solicitud de información que hiciera en 1820-1821 no era para nada nueva entre los intendentes, ${ }^{84}$ queda claro que la debilidad del mandatario resultó de cierta apatía de su funcionariado frente a los acontecimientos relacionados con Agustín de Iturbide. ${ }^{85}$

${ }^{82}$ El Sol, México, 18 de agosto y 4 de diciembre de 1824.

${ }^{83}$ Acta del congreso constituyente del estado de México, 12 de noviembre de 1824, El Sol, México, 15 de noviembre de 1824.

${ }^{84}$ Ernest Sánchez Santiró, "Los libros de la razón general de Real Hacienda como instrumentos de gobierno del erario de Nueva España (1768-1818): una obra inconclusa”, Estudios de Historia Novohispana, n. 57 (julio-diciembre 2017): 79-96.

${ }^{85}$ Vicente Rocafuerte, Bosquejo ligerísimo de la revolución de Mégico desde el grito de Iguala hasta la proclamación imperial de Iturbide (Filadelfia: Imprenta de Teracrouef y Naroajeb, 1822), 72. 
Y en todo caso, la actitud resultó en informes sobre ingresos, gastos y deuda muy tardíos que no sirvieron al virrey y sí fueron muy útiles para las tropas trigarantes. Y si bien, como nos dice Rodrigo Moreno, éstas contaban con sus propias tesorerías, me parece que, al paso de los meses y las adhesiones, el ejército hizo uso de la estructura administrativa de los ayuntamientos - al socaire de las diputaciones provinciales que aún no consolidaban sus propias oficinas financieras-y siguiendo los postulados del artículo 15 del Plan de Iguala que estipulaba que se mantendrían las oficinas tal y como estaban al momento de la adhesión.

Lo que sí es plenamente evidente de las realidades comprendidas entre septiembre de 1821 y agosto de 1824 es el desorden de la administración financiera pública. Tal desorden se percibe en la falta de uniformidad con la que operaba el financiamiento de obras de corte nacional, como era el pago de las dietas y viáticos de los diputados representantes en los cuatro congresos que se organizaron en el periodo. Esta falta de uniformidad es en parte el resultado de la escasez de recursos para financiar esa tarea, pero también es el resultado de que la tesorería de la ciudad de México - la que debía ser caja matriz del resto del espacio recién independizado- solamente se ocupaba de los pagos ordenados por Iturbide. Y estos pagos, generalmente destinados al ejército, dependían de los recursos disponibles, ya fuera el fondo dotal de la Casa de Moneda, como se mostró en el cuerpo del trabajo, acaso algunas otras rentas arrendadas y quizá - aunque difícilmente- las aduanas marítimas. Y es probable que el resto de los recursos como alcabalas, naipes, tabaco, etcétera, se los quedara la diputación provincial de México que celosamente los cuidaba para el pago de sus propias necesidades.

La Junta Provisional Gubernativa muestra conciencia de que el problema era mayúsculo. La discusión sobre la posibilidad de una superintendencia que, a decir de Muñoz Rodríguez, en el pasado fue creada para servir acciones militares, llevaba consigo la idea de que tal personaje y sus subordinados los intendentes controlarían los impuestos. Esto en sí no representaba el problema principal; lo más grave de la propuesta para establecer un superintendente significaba para las aún débiles diputaciones provinciales una cuña adentro de sus territorios cuya capacidad coactiva/tributaria no excluía la búsqueda de acuerdos con las oligarquías locales. Si colocamos en el mismo término a superintendente e intendentes, vale considerar la siguiente cita literal de Muñoz Rodríguez: 
[...] los superintendentes, al centralizar las competencias fiscalizadoras [...] crearon una burocracia relativamente amplia. Las superintendencias contaban con escribanos, abogados, contadores, tesoreros, fieles administradores repartidos por los diversos distritos e, incluso, con guardas que escoltaban a estos ministros en sus labores de inspección y recaudación por las poblaciones que tenían encomendadas. El peligro que entrañaba una comisión de rentas reales era elevado debido a la posición social que ostentaban en muchas ocasiones los mismos defraudadores -miembros de las oligarquías locales-y al empleo tan habiltual [...] de métodos violentos en la resolución de conflictos. ${ }^{86}$

Al parecer los recursos que se generaron provenían principalmente de los ayuntamientos, recursos que se habían generado para un fin específico en la localidad pero que tuvieron que destinarse al financiamiento de las prioridades provinciales y nacionales. Las diputaciones y juntas provinciales también generaron sus propios recursos o les fueron otorgados por leyes nacionales, como es el caso de alguno de los programas de contribución directa y varios préstamos. Pero las diputaciones provinciales no tenían una estructura administrativa capaz de recoger estas contribuciones y préstamos, por lo que dependieron de las capacidades de los ayuntamientos. No tengo testimonio de que éstos se negaran a entregar los recursos a la diputación, pero sí de que, así como les era más fácil recolectar contribuciones directas y préstamos, también era más fácil para los contribuyentes dar explicaciones de por qué no podían hacer frente a tales cargas. Por otro lado, un aspecto que no menciono en el trabajo que también explica por qué el gobierno nacional carecía de recursos provenientes de las provincias era porque la creación de las capitanías generales había dado mucha ponderación a los militares, quienes priorizaron la asignación de los recursos a las labores militares; esto no era ilegal, pero es probable que no se ocuparan de informar ni rendir cuenta alguna. Sólo en los lugares en donde prevalecía una estructura de tesorería y contaduría - es decir, ministros de la hacienda nacional e intendente- es que se puede hablar de cierto tipo de información dirigida hacia la ciudad de México.

Me parece también importante apuntar a la enorme dificultad de establecer una representación de la nación que equilibrara al poder ejecutivo en la imagen de un generalísimo, almirante, soberano, etcétera. Tan grande fue la necesidad de hacer esto que, para financiar a tales representantes, la

${ }^{86}$ Muñoz Rodríguez, “El superintendente austriaco y el intendente borbónico...”, § 3, 5 , 10 y 14. 
nueva nación debió instruir a sus diputaciones provinciales que crearan impuestos propios para poder pagar dietas y viáticos de los nuevos diputados. El exhorto desde la ciudad de México a las diputaciones tuvo implicaciones administrativas de gran relevancia, toda vez que obligó a las juntas provinciales a construir una administración propia para poder administrar estos recursos y, por lo demás, habérselo dejado a los ayuntamientos habría hecho el problema aún peor de lo que fue en los años siguientes.

La decisión de la junta provisional gubernativa sobre el establecimiento de un ministerio y no de una superintendencia de hacienda muestra un atisbo, quizá inconsciente, de que la administración que se recibía del dominio español no era viable para el caso de la nueva nación. Parecería como si se hubieran percatado de que, con el debilitamiento de todo el aparato intendencial, la totalidad de la administración heredada de la etapa virreinal se deterioraría hasta el grado de tener que fabricar un nuevo andamiaje. En noviembre de 1823 la conciencia de esta necesidad la expresó el ministro de hacienda Francisco de Arrillaga. Fue sobre esta Memoria de Hacienda sobre la que se construyó el edificio administrativo de la primera república federal.

\section{FuENTES}

\section{Documentales}

Archivo General de la Nación (AGN), Ciudad de México.

\section{Hemerografía}

Águila Mexicana

El Sol

\section{Bibliografía}

Actas constitucionales mexicanas 1821-1824. Introducción y notas de José Barragán Barragán. 10 v. México: Universidad Nacional Autónoma de México, Instituto de Investigaciones Jurídicas, 1980.

Arnold, Linda. Burocracia y burócratas en México, 1742-1835. México: Consejo Nacional para la Cultura y las Artes/Grijalbo, 1991. 
Benson, Nettie Lee. The Provincial Deputation in Mexico. Harbinger of Provincial Autonomy, Independence, and Federalism. Austin: University of Texas Press, 1992. Canga Argüelles, José. Diccionario de hacienda con aplicación a España. 2 v. Madrid: Imprenta de don Marcelino Calero y Portocarrero, 1833-1834.

Chust, Manuel. "Federalismo avant la lettre en las cortes hispanas, 1810-1821." En El establecimiento del federalismo en México, 1821-1827, coordinación de Josefina Zoraida Vázquez, 77-114. México: El Colegio de México, 2003.

Colección de los decretos y órdenes que han expedido las cortes generales y extraordinarias desde 24 de febrero de 1813 hasta 14 de setiembre del mismo año, en que terminaron sus sesiones. V. 4. Madrid: Imprenta Nacional, 1820.

"Congreso de los Diputados. Diario de sesiones. Serie histórica", acceso el 9 de septiembre de 2019. https://app.congreso.es/est_sesiones/.

Dubet, Anne. La hacienda real de la nueva planta (1713-1726), entre fraude y buen gobierno. El caso Verdes Montenegro. Madrid: Fondo de Cultura Económica de España, 2015.

Dublán, Manuel y José María Lozano. Legislación mexicana o colección completa de las disposiciones legislativas expedidas desde la independencia de la República ordenada. 42 v. México: Imprenta del Comercio, 1876-1912.

Frasquet, Ivana. Las caras del águila: del liberalismo gaditano a la república federal mexicana, 1820-1824. Castelló de la Plana: Universitat Jaume I, 2008.

Galván Hernández, José Luis. “Al mejor servicio del rey: la Junta Superior de Real Hacienda en Nueva España, 1786-1821.” Tesis de licenciatura. Instituto de Investigaciones Dr. José María Luis Mora, 2017.

Galván Rivera, Mariano, Francisco del Moral, e Isidro Rafael Gondra. Colección de órdenes y decretos de la Soberana Junta Provisional Gubernativa y soberanos congresos generales de la nación mexicana. 8 v. México: Imprenta de Galván a cargo de M. Arévalo, 1829-1840.

Garrido Asperó, María José. “¿Quién paga los gastos de la representación política? Las dietas de los diputados de la provincia de México en el primer Congreso Constituyente mexicano." Secuencia, n. 87 (enero-abril 2013): 31-48.

Gortari, Hira de. "La organización política territorial de la Nueva España a la primera república federal, 1786-1827." En El establecimiento del federalismo en México, 1821-1827, coordinación de Josefina Zoraida Vázquez, 39-76. México: El Colegio de México, 2003.

Guerrero Orozco, Omar. "Estudio introductorio.” En Principios de administración pública, Charles-Jean Bonnin, compilación y estudio introductorio de Omar Guerrero. México: Fondo de Cultura Económica, 2004.

Gutiérrez Núñez, Netzahualcóyotl Luis. "La real hacienda y la ordenanza de intendentes de 1786: ensayo sobre su estructura y funcionamiento a partir del caso 
de Valladolid de Michoacán, 1786-1820.” En Historia de la hacienda pública en Michoacán, 1786-1951, coordinación de Jorge Silva Riquer, 19-84. Morelia: Universidad Michoacana de San Nicolás de Hidalgo/El Colegio de San Luis, 2015.

Hernández Jaimes, Jesús. La formación de la hacienda pública mexicana y las tensiones centro-periferia, 1821-1835. México: Instituto de Investigaciones Dr. José María Luis Mora/El Colegio de México/Universidad Nacional Autónoma de México, Instituto de Investigaciones Históricas, 2013.

Hernández y Dávalos, Juan E. Colección de documentos para la historia de la guerra de independencia de México de 1808 a 1821. 6 v. México: José María Sandoval Impresor, 1877-1881.

La Diputación Provincial de Guanajuato. Actas de sesiones, 1822-1824. Estudio introductorio de José Antonio Serrano Ortega. México: Instituto de Investigaciones Dr. José María Luis Mora/El Colegio de Michoacán, 2016.

La Diputación Provincial de Nueva Galicia. Actas de sesiones, 1820-1822. Estudio introductorio de Jaime Olveda, edición y sumario de Beatriz Rojas. México: Instituto de Investigaciones Dr. José María Luis Mora/Universidad de Guadalajara, 2004.

La Diputación Provincial de Provincias Internas de Occidente (Nueva Vizcaya y Durango). Actas de sesiones, 1821-1823. Estudio introductorio de César Navarro Gallegos. México: Instituto de Investigaciones Dr. José María Luis Mora, 2006.

La Diputación Provincial de San Luis Potosí. Actas de sesiones, 1821-1824. Estudio introductorio de María Isabel Monroy Castillo. 2 v. México: Instituto de Investigaciones Dr. José María Luis Mora/El Colegio de San Luis, 2012.

La Diputación Provincial de Zacatecas. Actas de sesiones, 1822-1823. Edición estudio introductorio y sumario de Beatriz Rojas Nieto. México: Instituto de Investigaciones Dr. José María Luis Mora/Gobierno del Estado de Zacatecas, 2003.

Jáuregui, Luis. La real hacienda de Nueva España. Su administración en la época de los intendentes, 1786-1821. México: Universidad Nacional Autónoma de México, Facultad de Economía, 1999.

Ludlow, Leonor. "Élites y finanzas públicas durante la gestación del Estado independiente, 1821-1824." En Hacienda y política. Las finanzas públicas y los grupos de poder en la primera República Federal Mexicana, coordinación de José Antonio Serrano Ortega y Luis Jáuregui, 79-114. México: El Colegio de Michoacán/ Instituto de Investigaciones Dr. José María Luis Mora, 1998.

Marichal, Carlos. Bankruptcy of Empire. Mexican Silver and the Wars between Spain, Britain and France, 1760-1810. Nueva York: Cambdrige University Press, 2007. 
Marichal, Carlos. La bancarrota del virreinato. Nueva España y las finanzas del imperio español, 1780-1810. México: El Colegio de México/Fideicomiso de las Américas, 1999.

Moreno Gutiérrez, Rodrigo. La trigarancia. Fuerzas armadas en la consumación de la independencia Nueva España, 1820-1821. México: Universidad Nacional Autónoma de México, Instituto de Investigaciones Históricas/Fideicomiso Teixidor, 2016.

Muñoz Rodríguez, Julio D. “El superintendente austriaco y el intendente borbónico. La evolución de un modelo de gestión de los recursos fiscales en la Monarquía hispánica.” En Las monarquías española y francesa (siglos XVI-XVIII) ¿Dos modelos políticos?, coordinación de Anne Dubet y José Javier Ruíz Ibáñez, 131141. Madrid: Casa de Velázquez, 2010, acceso el 15 de septiembre de 2019. http://books.openedition.org/cvz/970.

Ortiz Escamilla, Juan. Guerra y gobierno: los pueblos y la independencia de México. Sevilla: Universidad de Sevilla/El Colegio de México/Instituto de Investigaciones Dr. José María Luis Mora, 1997.

Pietschmann, Horst. Las reformas borbónicas y el sistema de intendencias en Nueva España: un estudio político administrativo. México: Fondo de Cultura Económica, 1996.

Rocafuerte, Vicente. Bosquejo ligerísimo de la revolución de Mégico desde el grito de Iguala hasta la proclamación imperial de Iturbide. Filadelfia: Imprenta de Teracrouef y Naroajeb, 1822.

Romero Sotelo, María Eugenia. Minería y guerra: la economía de Nueva España, 18101821. México: El Colegio de México/Universidad Nacional Autónoma de México, Facultad de Economía, 1997.

Sánchez Santiró, Ernest. “Guerra y restauración del antiguo régimen fiscal en Nueva España: la Junta Menor de Arbitrios de 1815." Jahrbuch für Geschichte Lateinamerikas, n. 48 (2011): 57-81.

Sánchez Santiró, Ernest, compilación y prólogo. Documentos para la historia fiscal del erario de Nueva España, (1808-1821). México: Instituto de Investigaciones Dr. José María Luis Mora, 2017.

Sánchez Santiró, Ernest. "Genealogía, contenido y consecuencias de un documento contable: las Relaciones de valores y distribución de la Real Hacienda de Nueva España en el quinquenio de 1744 a 1748." En Relaciones de valores y distribución de la real hacienda de Nueva España, 1744-1748. Estudio introductorio de Ernest Sánchez Santiró. México: Instituto de Investigaciones Dr. José María Luis Mora/El Colegio de San Luis/El Colegio de Michoacán/Archivo General de la Nación México, 2014. [CD con el documento contable.] 
Sánchez Santiró, Ernest. La imperiosa necesidad: crisis y colapso del erario de Nueva España (1808-1821). México: Instituto de Investigaciones Dr. José María Luis Mora/El Colegio de Michoacán, 2016.

Sánchez Santiró, Ernest. “Los libros de la razón general de Real Hacienda como instrumentos de gobierno del erario de Nueva España (1768-1818): una obra inconclusa." Estudios de Historia Novohispana, n. 57 (julio-diciembre 2017): 79-96.

Sánchez Santiró, Ernest. "Los mecanismos de financiamiento de la contrainsurgencia, 1810-1821." En El sustento económico de las revoluciones en México, coordinación de Leonor Ludlow, 95-122. México: Universidad Nacional Autónoma de México, Instituto de Investigaciones Históricas, 2013.

Serrano Ortega, José Antonio. "Liberalismo y contribuciones directas en México, 1810-1835." En La trascendencia del liberalismo doceañista en España y en América, coordinación de Manuel Chust Calero e Ivana Frasquet Miguel, 187-210. Valencia: Generalitat Valenciana, Conselleria de Cultura, Educació i Esport, 2004.

Tena Ramírez, Felipe. Leyes fundamentales de México, 1808-1991. 16a. ed. México: Porrúa, 1991.

Tenenbaum, Barbara. "Sistema tributario y tiranía: las finanzas públicas durante el régimen de Iturbide, 1821-1823.” En Las finanzas públicas en los siglos XVIII-XIX, coordinación de Luis Jáuregui y José Antonio Serrano Ortega, 209-226. México: Instituto de Investigaciones Dr. José María Luis Mora/El Colegio de Michoacán/El Colegio de México/Universidad Nacional Autónoma de México, Instituto de Investigaciones Históricas, 1998.

TePaske, John, J. "La crisis financiera del virreinato de Nueva España a fines de la colonia.” En Las finanzas públicas en los siglos XVIII-XIX, coordinación de Luis Jáuregui y José Antonio Serrano Ortega, 90-109. México: Instituto de Investigaciones Dr. José María Luis Mora/El Colegio de Michoacán/El Colegio de México/Universidad Nacional Autónoma de México, Instituto de Investigaciones Históricas, 1998.

Valle Pavón, Guillermina del. "El monopolio del tabaco en Veracruz durante la guerra de independencia.” En Revisión histórica de la guerra de independencia en Veracruz, coordinación de Juan Ortiz Escamilla, 53-72. México: Universidad Veracruzana, 2008.

Veytia, M. R. "Naturaleza, límites y organización general de la administración." Revista de Administración Pública. Edición especial en memoria del maestro y primer presidente del INAP: Gabino Fraga. La concepción de la administración pública a través del derecho administrativo mexicano. Pasado y presente, n. 1982 (noviembre 1982): 195-209 [reproducción del trabajo de 1851-1852]. 
Es doctor en Historia por El Colegio de México. Forma parte del Sistema Nacional de Investigadores. Trabaja en proyectos relacionados con la modernización fiscal en América Latina, siglos xvin al xx. Ha publicado diversos estudios sobre este tema y desde hace varios años se ocupa también de los estudios de las relaciones fiscales de los estados del noreste mexicano con la capital republicana. En materia de divulgación, es autor de un capítulo de la Nueva historia mínima de México (El Colegio de México, 2004), así como de la Historia económica general de México (El Colegio de México/ Secretaría de Economía, 2010); también es coautor en la Nueva historia general de México (El Colegio de México, 2010). 
